\title{
A Bibliometric Analysis of the Impacts of Air Pollution on Children
}

\author{
Jinfang Sun ${ }^{1}$, Zhichao Zhou ${ }^{2}$, Jing Huang ${ }^{3}$ and Guoxing $\mathrm{Li}^{3, *}$ (D) \\ 1 Office of Epidemiology, Chinese Center for Disease Control and Prevention, Beijing 102206, China; \\ sunjf@chinacdc.cn \\ 2 Peking University Health Science Library, Beijing 100191, China; zhouzc1987@bjmu.edu.cn \\ 3 Department of Occupational and Environmental Health Sciences, Peking University School of Public Health, \\ Beijing 100191, China; jing_huang@bjmu.edu.cn \\ * Correspondence: liguoxing@bjmu.edu.cn; Tel.: +86-10-8280-1522
}

Received: 2 February 2020; Accepted: 14 February 2020; Published: 17 February 2020

check for updates

\begin{abstract}
In recent years, many researchers have investigated the association between air pollution and children. However, there has been little research to provide a macroscopic overview in this field. The aim of this study is to characterize the scientific production around the world in this area and map the trends. The relevant literature was searched from 1999 to 2018. To guarantee the quality of the literature, we combined the PubMed and WoS databases. The built-in statistics tools of the Web of Science website were used to display the trend of articles published by year and the distribution of journals. By CiteSpace (5.5.R2), the reference co-citation and burst keywords were extracted. In total, 15,999 target English documents were obtained. We summarized the characteristics of published documents, of research institutes' cooperation, and of the contents. As part of a research hotspot, ten clusters are presented, four popular topics are elaborated. Twenty-four burst words were obtained and analyzed. China has received more attention in recent years. Researchers in this field could carry out more cohorts' studies and fine particulate matter is one good air pollution index. Household air pollution exposure and children's lung function should be paid more attention.
\end{abstract}

Keywords: air pollution; children; research trend; bibliometric study

\section{Introduction}

Air pollution has become a global public health problem. Based on the global burden of disease (GBD) report, Ambient $\mathrm{PM}_{2.5}$ was the fifth-ranking mortality risk factor in 2015, outdoor air pollution has a number of adverse effects on human health [1,2]. Due to the fact that children's body systems are still developing, they are more vulnerable than adults if exposed to harmful pollutants [3]. Plenty of results concerning the impact of air pollution on children have been reported [4]. Nevertheless, most of the literature focuses on specific diagnosis, intervention, and policies in the area. Little research has attempted to explore it from a macro perspective.

The associations between air pollution and children's health have been studied in numerous studies [5-7]. Mansourian found that $\mathrm{PM}_{10}$ and $\mathrm{SO}_{2}$ concentrations had statistically increased the number of respiratory admissions of children in Isfahan, Iran [8]. Khaniabadi et al. suggested that children and other vulnerable groups should be protected to reduce the adverse health impact of air pollution [9]. Siddique et al. obtained a positive association between the $\mathrm{PM}_{10}$ level in Delhi's air and the prevalence of lower respiratory tract symptoms [10]. This research confirmed the adverse effects of air pollution on children's health.

Bibliometric analysis, a well-established research method in information and library science, has been commonly used for revealing research outputs [11]. Bibliometric analyzes are important tools to 
evaluate and quantify the growth of literature for a particular subject. The bibliometric method has been used in different contexts to investigate data showing increases in the number of publications and identification of the main authors, research institutions, and countries [12]. In this study, we retrieve the therapy-related papers of the last 20 years in the main bibliographic databases, analyze them from the perspective of literature publication, so as to reacquaint the transition and inheritance of the impacts of air pollution on children, and meanwhile reveal the possible research focuses for the future, which could help researchers in their topic selection in this field. Bibliometrics is a useful method to explore the most impactful authors, countries/regions, construct collaboration networks, and identify research key topics in particular areas. In the present study, a bibliometric analysis is conducted to (1) determine the research landscape of air pollution on children in terms of the year, journals, institutions, keywords, and references; (2) identify the cooperation among institutions; and (3) explore the hot topics and developments in the future.

\section{Materials and Methods}

\subsection{Literature Sources}

PubMed is the most comprehensive biomedical literature database worldwide, which is developed and maintained by the National Center for Biotechnology Information at the U.S. National Library of Medicine. PubMed comprises more than 28 million citations for biomedical literature from MEDLINE, life science journals, and online books. Hence, we chose PubMed as the English literature source. In order to search the literature about impacts of air pollution on children as comprehensively as possible, we performed literature retrieval both in PubMed and the Web of Science Core Collection on 23 June 2019.

\subsection{Search Strategy}

At the beginning, we found out whether the search word was covered by the Medical Subject Headings (MeSH) database, which is the National Library of Medicine's controlled vocabulary thesaurus used for indexing articles for PubMed. If not, the word would be searched as a text word. For the concept of air pollution, we found several MeSH terms that are closely related to it, such as air pollution, air pollutants, and particulate matter. Next, some MeSH terms regarding the main monitoring component of air pollution was also included, such as Nitrogen Dioxide, Sulfur Dioxide, Ozone, Vehicle Emissions, and Carbon monoxide. Considering that the same concept may be expressed in different ways in scientific papers, we also searched the concept of air pollution above-mentioned in the text word. In addition, atmospheric pollution, inhalable particles, and inhalable particulate matter were also included in the search strategy as text words. According to the Convention on the Rights of the Child, issued by United Nations, a child means every human being below the age of eighteen years unless under the law applicable to the child, majority is attained earlier [13]. Therefore, for the concept of child in our research, the corresponding terms in the Mesh database are Infant, Child, and Adolescent, which are connected with logical operator "OR", and we also add the Pediatrics as MeSH term. The logical link between the concepts of air pollution and child is "AND", the search time is limited to the past two decades, which is 1999-2018, 12,156 target English documents were obtained.

Figure 1 shows the flowchart of our research. First, we got 12,156 target English documents through PubMed. PubMed is a comprehensive biomedical abstract database, but it cannot guarantee the quality of the literature, so we used the WoS database to again retrieve the literatures from the PubMed database and keep the high-quality literature. Then, we searched the literature about the impact of air pollution on children in the Web of Science database with the above keywords. In total, 9503 target English documents were obtained. Finally, we combined two datasets and just included the literature that are published in three types (article, review, letter) from 1999 to 2018, so we obtained 15,999 documents. The complete literature retrieval strategy is presented in Tables S1 and S2. 


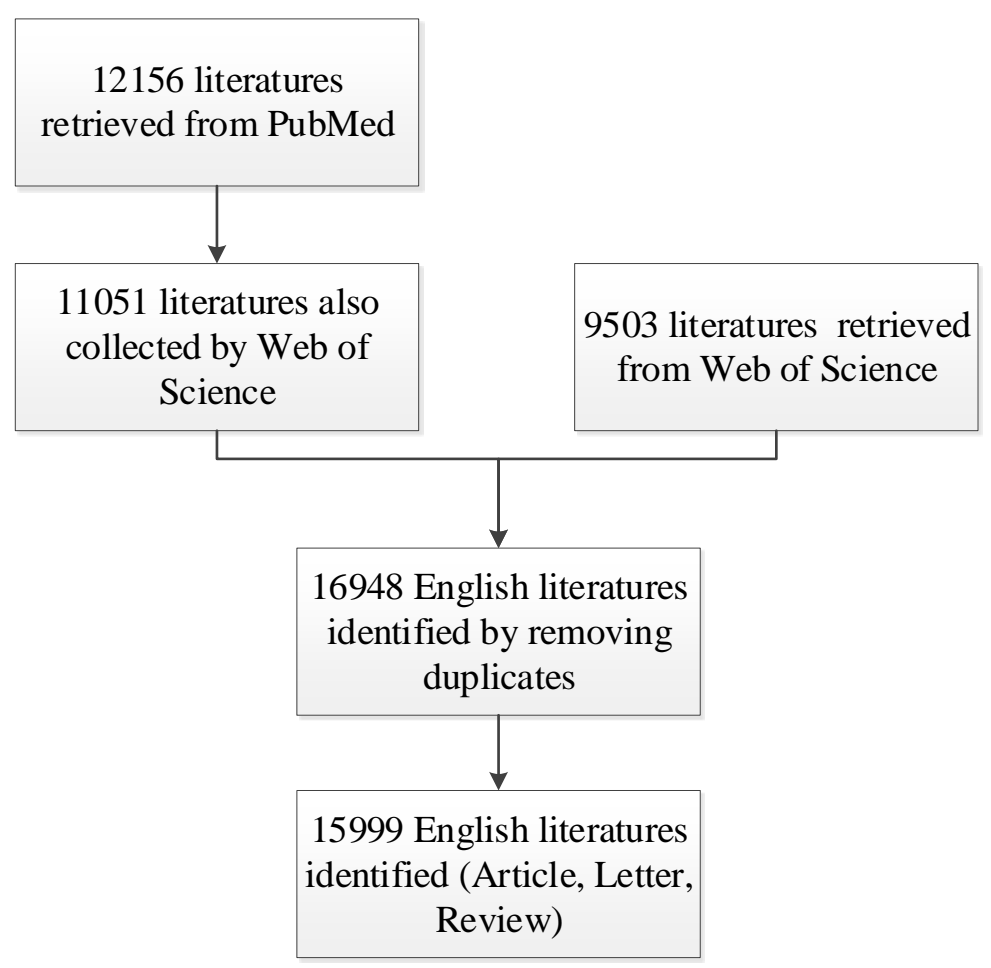

Figure 1. The flowchart of the research to search papers in databases.

\subsection{Data Visualization and Analysis}

The identified articles were systematically analyzed by the Web of Science website and CiteSpace (5.5.R2) (https://sourceforge.net/projects/citespace/) [14]. The Web of Science website has built-in statistics tools to display the trend of articles published by year and the distribution of journals. CiteSpace has been continuously developed to meet the needs for visual analytic tasks of science mapping. CiteSpace takes a set of bibliographic records as its input and models the intellectual structure of the underlying domain in terms of a synthesized network on the basis of a time series of networks derived from each year's publications. CiteSpace supports several types of bibliometric studies, including collaboration network analysis, co-word analysis, author co-citation analysis, document co-citation analysis, and text and geospatial visualizations. In this study, we focus on the document co-citation analysis within the period of time between 1999 and 2018 and mine research hotspots and further discover and predict research frontiers by detecting the occurrence of mutation words in topics, abstracts, and keywords.

\section{Results}

\subsection{The Annual Trend of Global Publications}

Figure 2 showed the trend of publication number in the past twenty years. A total of 15,999 articles matched the retrieval criteria and were included for further analysis. The results indicated a consistently increasing trend from 498 articles in 1999 to 1213 articles in 2018. 


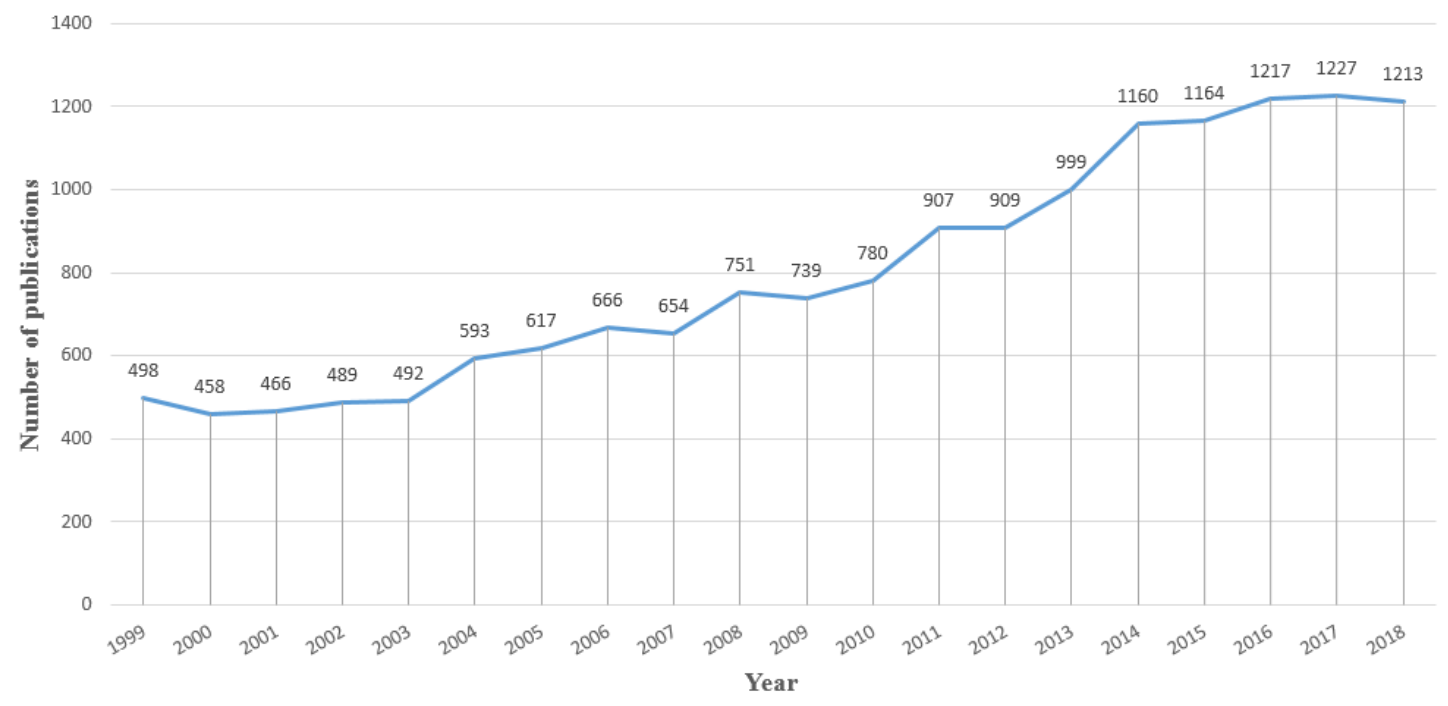

Figure 2. Global literature about air pollution and children published from 1999-2018.

\subsection{Analysis of Core Journals}

A total of 2052 scholarly journals have published articles regarding the research on the impact of air pollution on children. According to the Bradford law, literature on a topic is often concentrated in core journals. We usually chose the 10 or 20 academic journals with the most publications covering more than $30 \%$ of the articles for analysis, so as to make the results more representative [15-18].

The top 20 journals are presented in Table 1. The top 20 journals contributed 4885 (30.53\%) articles. ENVIRONMENTAL HEALTH PERSPECTIVES (IF $=8.049)$ published the highest number of articles (596 articles, 3.73\%), followed by ENVIRONMENTAL RESEARCH (IF = 5.026, 450 articles, 2.81\%), SCIENCE OF THE TOTAL ENVIRONMENT (IF = 5.589, 377 articles, 2.36\%), INTERNATIONAL JOURNAL OF ENVIRONMENTAL RESEARCH AND PUBLIC HEALTH (IF $=2.468,233$ articles, $2.01 \%$ ). Among the top 20 journals, around $75 \%$ were from the United States (nine) and England (six).

Table 1. The top 10 journals of research on air pollution and children.

\begin{tabular}{cccccc}
\hline Rank & Journal & $\boldsymbol{N ~ ( \% )}$ & Country & IF (2018) & Classification \\
\hline 1 & $\begin{array}{c}\text { ENVIRONMENTAL HEALTH } \\
\text { PERSPECTIVES }\end{array}$ & $596(3.73 \%)$ & USA & 8.049 & $(1-3)$ \\
\hline 2 & $\begin{array}{c}\text { ENVIRONMENTAL } \\
\text { RESEARCH }\end{array}$ & $450(2.81 \%)$ & USA & 5.026 & $(1,2)$ \\
\hline 3 & $\begin{array}{c}\text { SCIENCE OF THE TOTAL } \\
\text { ENVIRONMENT }\end{array}$ & $377(2.36 \%)$ & NETHERLANDS & 5.589 & $(1)$ \\
\hline & $\begin{array}{c}\text { INTERNATIONAL JOURNAL } \\
\text { OF ENVIRONMENTAL } \\
\text { RESEARCH AND PUBLIC } \\
\text { HEALTH }\end{array}$ & $322(2.01 \%)$ & SWITZERLAND & 2.468 & $(1,2)$ \\
\hline 5 & $\begin{array}{c}\text { ENVIRONMENT } \\
\text { INTERNATIONAL }\end{array}$ & $303(1.89 \%)$ & USA & 7.943 & $(1)$ \\
\hline 6 & PLOS ONE & $255(1.59 \%)$ & USA & 2.776 & $(4)$ \\
\hline 7 & INDOOR AIR & $242(1.51 \%)$ & DENMARK & 4.710 & $(2,5,6)$ \\
\hline
\end{tabular}


Table 1. Cont.

\begin{tabular}{|c|c|c|c|c|c|}
\hline Rank & Journal & $N(\%)$ & Country & IF (2018) & Classification \\
\hline 8 & $\begin{array}{c}\text { JOURNAL OF ALLERGY } \\
\text { AND CLINICAL } \\
\text { IMMUNOLOGY }\end{array}$ & $228(1.43 \%)$ & USA & 14.110 & $(7,8)$ \\
\hline 9 & $\begin{array}{l}\text { ATMOSPHERIC } \\
\text { ENVIRONMENT }\end{array}$ & $221(1.38 \%)$ & ENGLAND & 4.012 & $(1,9)$ \\
\hline 10 & PEDIATRICS & $209(1.31 \%)$ & USA & 5.401 & (10) \\
\hline 11 & $\begin{array}{l}\text { AMERICAN JOURNAL OF } \\
\text { RESPIRATORY AND } \\
\text { CRITICAL CARE MEDICINE }\end{array}$ & $199(1.244 \%)$ & USA & 16.494 & $(11-13)$ \\
\hline 12 & ENVIRONMENTAL HEALTH & $198(1.237 \%)$ & ENGLAND & 4.430 & $(1,2)$ \\
\hline 13 & $\begin{array}{l}\text { EUROPEAN RESPIRATORY } \\
\text { JOURNAL }\end{array}$ & $174(1.087 \%)$ & ENGLAND & 11.807 & $(11)$ \\
\hline 14 & $\begin{array}{c}\text { NICOTINE TOBACCO } \\
\text { RESEARCH }\end{array}$ & $174(1.087 \%)$ & ENGLAND & 3.786 & $(2,14)$ \\
\hline 15 & BMC PUBLIC HEALTH & $167(1.044 \%)$ & ENGLAND & 2.567 & (2) \\
\hline 16 & JOURNAL OF ASTHMA & $167(1.044 \%)$ & USA & 2.081 & $(11,15)$ \\
\hline 17 & $\begin{array}{c}\text { OCCUPATIONAL AND } \\
\text { ENVIRONMENTAL } \\
\text { MEDICINE }\end{array}$ & $156(0.975 \%)$ & ENGLAND & 3.556 & (2) \\
\hline 18 & $\begin{array}{c}\text { ENVIRONMENTAL } \\
\text { SCIENCE AND POLLUTION } \\
\text { RESEARCH }\end{array}$ & $155(0.969 \%)$ & GERMANY & 2.914 & (1) \\
\hline 19 & $\begin{array}{l}\text { INTERNATIONAL JOURNAL } \\
\text { OF HYGIENE AND } \\
\text { ENVIRONMENTAL HEALTH }\end{array}$ & $147(0.919 \%)$ & GERMANY & 4.379 & $(2,16)$ \\
\hline 20 & $\begin{array}{c}\text { JOURNAL OF EXPOSURE } \\
\text { SCIENCE AND } \\
\text { ENVIRONMENTAL } \\
\text { EPIDEMIOLOGY }\end{array}$ & $145(0.906 \%)$ & USA & 3.025 & $(1-3)$ \\
\hline
\end{tabular}

These literatures were classified by journal citation reports: (1) ENVIRONMENTAL SCIENCES, (2) PUBLIC, ENVIRONMENTAL \& OCCUPATIONAL HEALTH, (3) TOXICOLOGY, (4) MULTIDISCIPLINARY SCIENCES, (5) CONSTRUCTION \& BUILDING TECHNOLOGY, (6) ENGINEERING, ENVIRONMENTAL, (7) ALLERGY, (9) IMMUNOLOGY, (9) METEOROLOGY \& ATMOSPHERIC SCIENCES, (10) PEDIATRICS, (11) RESPIRATORY SYSTEM, (12) CRITICAL CARE MEDICINE, (13) EMERGENCY MEDICINE \& CRITICAL CARE, (14) SUBSTANCE ABUSE, (15) ALLERGY, (16) INFECTIOUS DISEASES.

\subsection{Characteristics of the Institutions Contribution}

Overall, 15,999 articles in research were published by 8425 institutions. Fifteen institutes were selected because of their critical role for scientific knowledge dissemination $[19,20]$. The list of top 15 institutions is presented in Table 2, which published about $24.81 \%$ of all the articles. Harvard University had the most publications (585), followed by the University of California, Berkeley (345), and Columbia University (311). In this table, mediating centrality represents the proportion of the connection between all other nodes in the cooperative network, and the value range is between 0 and 1 . The higher the value is, the more important the node is. 
Table 2. The top fifteen institutes during the period 1999-2018.

\begin{tabular}{ccc}
\hline Institution & N & Centrality \\
\hline Harvard University & 585 & 0.13 \\
University of California, Berkeley & 345 & 0.1 \\
United States Environmental Protection & 324 & 0.02 \\
Agency & 311 & 0.08 \\
Columbia University & 279 & 0.08 \\
US Centers for Disease Control and & 250 & 0.24 \\
Prevention & 248 & 0.11 \\
Utrecht University & 237 & 0.09 \\
University of Southern California & 229 & 0.04 \\
University of California, San Francisco & 223 & 0.17 \\
University of North Carolina at Chapel Hill & 213 & 0.09 \\
University Washington & 198 & 0.14 \\
Karolinska Institute & 178 & 0.3 \\
Johns Hopkins University & 178 & 0.14 \\
University of British Columbia & 172 & 0.07 \\
University of California Los Angeles &
\end{tabular}

In Figure 3, extensive cooperating relationships were observed among institutions. The greater the font size of the name, the more cooperation for the agency. The University of British Columbia, the University of Washington, and Utrecht University had thick purple outer rings, indicating that these nodes have a high degree of betweenness centrality and play an important role in mediating the composition of cooperative networks.

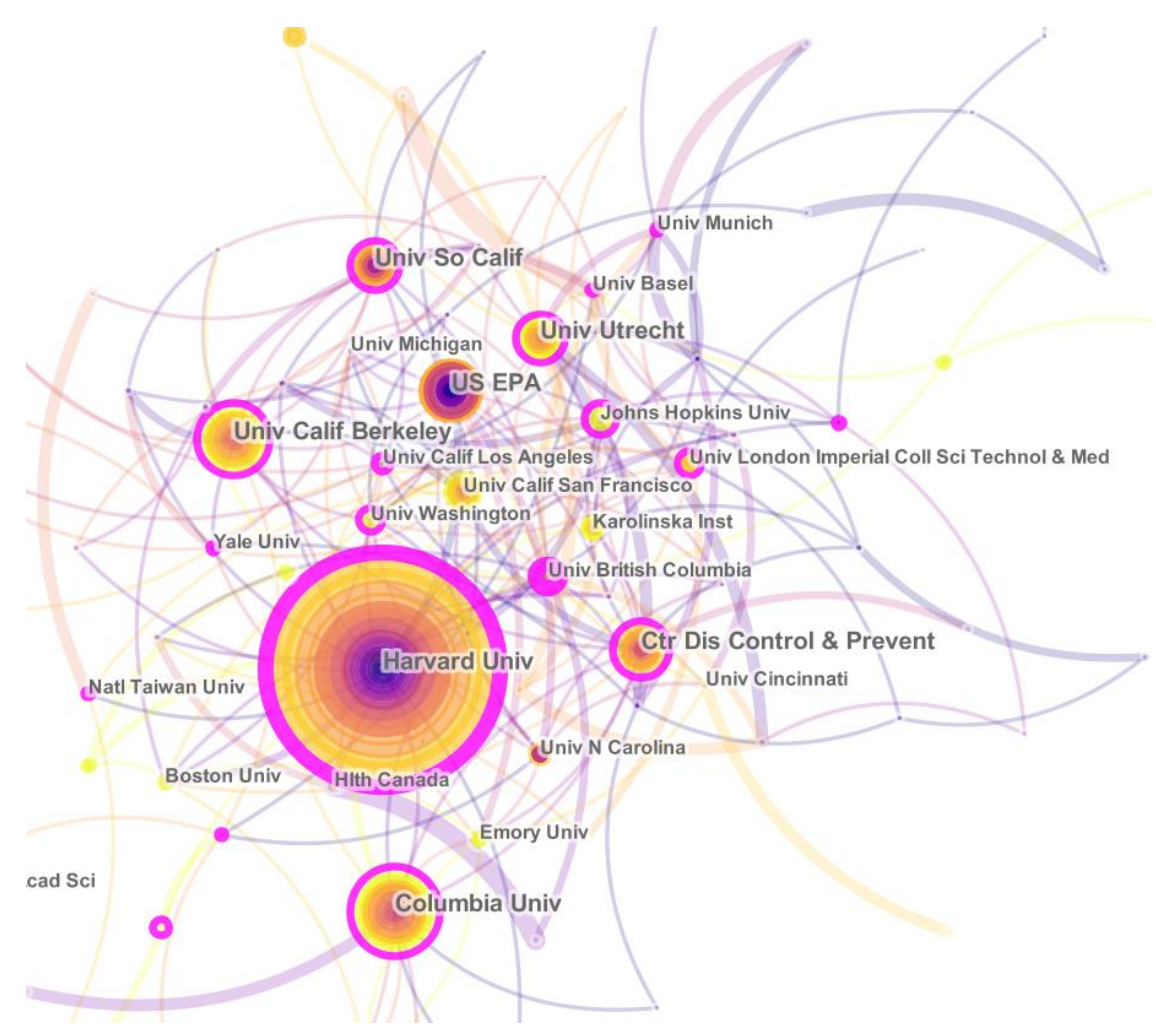

Figure 3. Map of active institutions in the research field from 1999 to 2018. The font size of the name represents the number of articles published by the institution. The purple ring of the circles indicates the core institution. The thickness of the curved connecting line represents the collaborative intensity between the institutions. 


\subsection{Analysis of Reference Co-Citation}

Table 3 is generated on the basis of publications between 1999 and 2018. The top 50 most cited publications in each two years are used to construct a network of references cited in that year. Then, individual networks are synthesized. The synthesized network contains 323,116 references. The network contains 377 nodes and was divided into 11 co-citation clusters. The four largest connected components include 104 nodes, which account for $56.76 \%$ of the entire network. The network has a modularity of 0.7346 . The average silhouette score of 0.3352 is relatively low, this is mainly because of the numerous small clusters. The first cluster is marked with "\#0 household air pollution", which indicates that the luster is cited by the articles on household air pollution. Eleven clusters differ from one another in the aspect of starting time, time span, or activeness, e.g., the duration of cluster "\#0 household air pollution" was the longest, lasting from 2007 to 2017. The cluster "\#1 nitrogen dioxide" appeared earlier, however it discontinued around 2009.

Table 3. Cluster analysis of literature from 1999-2018.

\begin{tabular}{cccccc}
\hline Cluster ID & Size & From & To & Activeness & Theme \\
\hline 0 & 64 & 2007 & 2017 & Active & Household air pollution \\
1 & 61 & 2001 & 2009 & Inactive & Nitrogen dioxide \\
2 & 60 & 1995 & 2004 & Inactive & Preterm delivery \\
3 & 29 & 1994 & 1999 & Inactive & Outdoor air pollution \\
4 & 29 & 2001 & 2010 & Inactive & Pregnancy outcome \\
5 & 25 & 2005 & 2015 & Active & Smoke-free legislation \\
6 & 24 & 1994 & 2002 & Inactive & High endotoxin level \\
7 & 22 & 1995 & 2001 & Inactive & Parental smoking \\
8 & 20 & 2008 & 2015 & Active & Autism spectrum disorder \\
9 & 15 & 2012 & 2017 & Active & Early childhood ear infection \\
10 & 10 & 2002 & 2006 & Inactive & Indoor environmental influence \\
\hline
\end{tabular}

\subsection{Analysis of Keywords and Burst Keywords}

According to the keyword co-occurrence analysis, 55 keywords were detected. The keywords with strong citation bursts were explored through CiteSpace, and 24 keywords with the strongest strength in the last decades were identified (Table 4) [21,22]. Strength means citation burst, and it represents the increasing frequency of keywords in the corresponding period. The appearance and duration time of the burst keywords represents the active time for these burst keywords. From 2009 to 2018, the burst key words changed from smoke ('nicotine', 'tobacco smoke', 'secondhand smoke') to fine particulate matter and ambient air pollution. The mechanism of PM2.5 on health focused on inflammation, not oxidation.

Table 4. The analysis of keywords from 1999 to 2018.

\begin{tabular}{ccccc}
\hline No. & Keywords & Strength & Begin & End \\
\hline 1 & Nicotine & 26.95 & 2009 & 2010 \\
2 & Tobacco smoke & 31.36 & 2009 & 2015 \\
3 & Indoor & 39.65 & 2009 & 2014 \\
4 & Quality & 33.27 & 2011 & 2018 \\
5 & Secondhand smoke & 34.36 & 2011 & 2015 \\
6 & Birth weight & 24.97 & 2011 & 2012 \\
\hline
\end{tabular}


Table 4. Cont.

\begin{tabular}{ccccc}
\hline No. & Keywords & Strength & Begin & End \\
\hline 7 & Indoor air pollution & 61.77 & 2011 & 2014 \\
8 & Developing country & 29.11 & 2013 & 2014 \\
9 & Particulate air pollution & 5.22 & 2013 & 2014 \\
10 & Intervention & 35.84 & 2013 & 2014 \\
11 & Young children & 13.70 & 2013 & 2014 \\
12 & Cohort & 33.90 & 2013 & 2018 \\
13 & Adult & 9.54 & 2013 & 2014 \\
14 & Impact & 59.26 & 2014 & 2018 \\
15 & China & 65.04 & 2014 & 2018 \\
16 & Polycyclic aromatic hydrocarbon & 22.64 & 2014 & 2018 \\
17 & Outcome & 34.96 & 2015 & 2016 \\
18 & Heavy metal & 68.63 & 2015 & 2018 \\
19 & Long term exposure & 35.50 & 2015 & 2016 \\
20 & Time series & 27.16 & 2015 & 2016 \\
21 & Oxidative stress & 27.16 & 2015 & 2016 \\
22 & Inflammation & 27.51 & 2015 & 2018 \\
23 & Fine particulate matter & 63.54 & 2015 & 2018 \\
24 & Ambient air pollution & 34.99 & 2015 & 2018 \\
\hline
\end{tabular}

\section{Discussion}

\subsection{General Information}

In this study, we found that the literature about air pollution and children showed an increasing trend. From 1999 to 2018, the number of related literatures increased from 498 to 1213. Such a phenomenon is consistent with research focus in recent years. In recent years, the impacts of air pollution on health have attracted world-wide attention because of its big disease burden. Numerous stations have been built to obtain air pollution exposure data, especially for $\mathrm{PM}_{2.5}$. Furthermore, many lab studies have been carried out to explore the mechanism of air pollution on health, through the inflammation field.

In this field, 3203 papers were published in the top ten journals, around $20.2 \%$ of the total literature. Such results suggested that these journals covered the field about air pollution and children. Academics in this field should submit their papers to these journals. In addition, papers on the relationship between air pollution and children were published in environmental journals, not clinical or children specific journals.

We also found a close cooperation among institutes. In the top ten institutes in this field, the top three institutes were Harvard University (585), the University of California, Berkeley (345), and Columbia University (311). They also have higher mediating centrality, which indicates that these agencies were very active in the cooperation network.

\subsection{Research Hotspots Analysis}

The clusters of the top 50 most cited publications in each two years were converged. And the modularity of the network is 0.7346 , which is usually considered to be relatively high, suggesting that the specialties in the impact of air pollution on children are clearly defined in terms of co-citation clusters. We just tried to divide the four active clusters into two categories: exposure (Clusters 0 and 5 ) and health outcome (Clusters 8 and 9).

Topic 1 (Clusters 0 and 5) demonstrated the exposure types which attracted more attention in recent epidemiological studies. It is well known that air pollution is a risk factor for the population, especially for children [23]. Considering that children spend time both indoors and outdoors, many studies consider both indoor and outdoor exposure [24]. Air pollution has adverse effects on cardiorespiratory effects, including asthma prevalence [25]. Researchers have come to explore the possible role of air 
pollution exposure in utero and early life. Based on one cohort in British Columbia in 1999 and 2000, they found early life exposure to $\mathrm{CO}, \mathrm{NO}, \mathrm{NO}_{2}, \mathrm{PM}_{10}, \mathrm{SO}_{2}$, and black carbon could significantly increase the risk of asthma and early childhood exposure to air pollutants should be avoided [26]. As for Cluster 5, 'passive smoke' is more precise than 'smoke-free legislation'. The ratio of children exposed to passive smoke is highest in the whole population [27] Compared with indoor air pollution, the study about passive smoke attracted less attention based on the duration time.

Topic 2 (Clusters 8 and 9) reflected the health outcomes that researchers focused on in recent years. Autistic disorder (AD) is a serious developmental disorder to which genetic and environmental factors likely contribute [28]. A lot of epidemiological studies provided evidence for the genetic interaction with environmental factors for autism [29]. One cross-section study in California found that ambient air pollutants, such as ozone and nitric oxide, are associated with autism [30]. As for Cluster 9, 'lung function' is more precise than 'early childhood ear infection'. Based on previous studies, the association between ambient air pollution and lung function was positive. Decreased lung function has a link with increased incidence of asthma [31]. Three separate cohorts were used to examine the association between air pollution and children lung function. The results showed that lung function improved with better air quality [32]. We recognized that 'lung function' should be paid more attention, compared with 'autism'.

\subsection{Burst Keywords}

Burst keywords refer to keywords heavily cited by articles over a period of time. Burst keywords are considered another important indicator of research hotspots or emerging trends over time. As seen in Table 4, the evolution of the burst keywords during the past decade shows the continuing progress in impacts of air pollution on children's health research. As for the exposure index, there is one obvious transition from the smoke-related index (such as nicotine, second-hand smoke) to the ambient air pollution index (fine particulate matter). Fine particulate matter has become one hotspot in china because of its bad air quality [33]. The related mechanism also is explored, and more studies have been carried out about inflammation [34]. As for the study design, there is also one obvious transition from time series to cohort. In current days, most cohort studies are carried out in developed countries with low air pollution exposure, so it is hard for researchers to get an accurate estimation about the impacts of high air pollution exposure on children [35]. The air pollution level in china is still well beyond the WHO recommended air quality criteria $\left(10 \mu \mathrm{g} / \mathrm{m}^{3}\right)$, so there is urgent need for a cohort study in this field in China [36-38].

\section{Conclusions}

On the basis of the quantitative analysis of co-citation and burst words analysis, researchers in this field can have a comprehensive understanding of the latest popular topics in the field of air pollution and children's health. Researchers in this field could carry out more cohort studies and fine particulate matter is one good air pollution index. Household air pollution exposure and children's lung function should be paid more attention to.

Supplementary Materials: The following are available online at http://www.mdpi.com/1660-4601/17/4/1277/s1, Table S1: Literature retrieval strategy in the PubMed. Table S2: Literature retrieval strategy in the Web of Science.

Author Contributions: Conceptualization, J.S. and G.L.; methodology, Z.Z.; formal analysis, Z.Z.; writing-original draft preparation, Z.Z., G.L., and J.H.; writing-review and editing, J.S.; project administration, G.L. and J.S. All authors have read and agreed to the published version of the manuscript.

Funding: This research was funded by the National Science and Technology Major Project of China (No.2018ZX10201001); National Natural Science Foundation of China (No. 41761144056).

Conflicts of Interest: The authors declare no conflict of interest. 


\section{References}

1. Burnett, R.; Chen, H.; Szyszkowicz, M.; Fann, N.; Hubbell, B.; Pope, C.A., 3rd; Apte, J.S.; Brauer, M.; Cohen, A.; Weichenthal, S.; et al. Global estimates of mortality associated with long-term exposure to outdoor fine particulate matter. Proc. Natl. Acad. Sci. USA 2018, 115, 9592-9597. [CrossRef]

2. Cohen, A.J.; Brauer, M.; Burnett, R.; Anderson, H.R.; Frostad, J.; Estep, K.; Balakrishnan, K.; Brunekreef, B.; Dandona, L.; Dandona, R.; et al. Estimates and 25-year trends of the global burden of disease attributable to ambient air pollution: An analysis of data from the Global Burden of Diseases Study 2015. Lancet 2017, 389, 1907-1918. [CrossRef]

3. He, Q.Q.; Wong, T.W.; Du, L.; Jiang, Z.Q.; Gao, Y.; Qiu, H.; Liu, W.J.; Wu, J.G.; Wong, A.; Yu, T.S.I. Effects of ambient air pollution on lung function growth in Chinese schoolchildren. Respir. Med. 2010, 104, 1512-1520. [CrossRef] [PubMed]

4. Sun, Z.L.; Zhu, D.M. Exposure to outdoor air pollution and its human health outcomes: A scoping review. PLoS ONE 2019, 14, e0216550. [CrossRef] [PubMed]

5. Tecer, L.H.; Tomac, N.; Karaca, F.; Kaplan, A.; Tuncer, T.; Aydin, H. The evaluation of the effect of air pollution on the health status of children in Zonguldak City, Turkey. Int. J. Environ. Pollut. 2009, 39, 352-364. [CrossRef]

6. Brunekreef, B.; Hoek, G. The Relationship between Low-Level Air-Pollution Exposure and Short-Term Changes in Lung-Function in Dutch Children. J. Expo. Anal. Environ. Epidemiol. 1993, 3, 117-128.

7. He, B.T.; Huang, J.V.; Kwok, M.K.; Yeung, S.L.A.; Hui, L.L.; Li, A.M.; Leung, G.M.; Schooling, C.M. The association of early-life exposure to air pollution with lung function at similar to 17.5 years in the “Children of 1997" Hong Kong Chinese Birth Cohort. Environ. Int. 2019, 123, 444-450. [CrossRef]

8. Mansourian, M.; Javanmard, S.H.; Poursafa, P.; Kelishadi, R. Air pollution and hospitalization for respiratory diseases among children in isfahan, iran. Ghana Med. J. 2010, 44, 138-143. [CrossRef]

9. Khaniabadi, Y.O.; Sicard, P.; Takdastan, A.; Hopke, P.K.; Taiwo, A.M.; Khaniabadi, F.O.; De Marco, A.; Daryanoosh, M. Mortality and morbidity due to ambient air pollution in Iran. Clin. Epidemiol. Glob. Health 2019, 7, 222-227. [CrossRef]

10. Siddique, S.; Ray, M.R.; Lahiri, T. Effects of air pollution on the respiratory health of children: A study in the capital city of India. Air Qual. Atmos. Health 2011, 4, 95-102. [CrossRef]

11. Bramness, J.G.; Henriksen, B.; Person, O.; Mann, K. A Bibliometric Analysis of European versus USA Research in the Field of Addiction. Research on Alcohol, Narcotics, Prescription Drug Abuse, Tobacco and Steroids 2001-2011. Eur. Addict. Res. 2014, 20, 16-22. [CrossRef] [PubMed]

12. Sun, X.; Guo, S.; Su, Q.; Chang, L.; Zhou, X. Advances in plastic and cosmetic surgery at home and abroad-A bibliometric analysis. Eur. Rev. Med. Pharmacol. Sci. 2013, 17, 2732-2754.

13. TUR Agency. Convention on the Rights of the Child [EB/OL]. Available online: http://www.unhcrorg/uk/ 4d9474b49.pdf (accessed on 20 May 2018).

14. Chen, C.M. CiteSpace II: Detecting and visualizing emerging trends and transient patterns in scientific literature. J. Am. Soc. Inf. Sci. Technol. 2006, 57, 359-377. [CrossRef]

15. Egghe, L. Applications of the Theory of Bradford Law to the Calculation of Leimkuhlers Law and to the Completion of Bibliographies. J. Am. Soc. Inf. Sci. 1990, 41, 469-492. [CrossRef]

16. Ouyang, W.; Wang, Y.D.; Lin, C.Y.; He, M.C.; Hao, F.H.; Liu, H.B.; Zhu, W.H. Heavy metal loss from agricultural watershed to aquatic system: A scientometrics review. Sci. Total Environ. 2018, 637, $208-220$. [CrossRef]

17. Liu, S.; Sun, Y.P.; Gao, X.L.; Sui, Y. Knowledge domain and emerging trends in Alzheimer's disease: A scientometric review based on CiteSpace analysis. Neural Regen. Res. 2019, 14, 1643-1650.

18. Huang, X.Q.; Fan, X.W.W.; Ying, J.; Chen, S.Y. Emerging trends and research foci in gastrointestinal microbiome. J. Transl. Med. 2019, 17, 67. [CrossRef]

19. Ghorbani, F.; Feizabadi, M.; Farzanegan, R.; Vaziri, E.; Samani, S.; Lajevardi, S.; Moradi, L.; Shadmehr, M.B. An Investigation of Topics and Trends of Tracheal Replacement Studies Using Co-Occurrence Analysis. Tissue Eng. Part. B-Rev. 2017, 23, 118-127. [CrossRef]

20. Su, Y.B.; Long, C.; Yu, Q.; Zhang, J.; Wu, D.; Duan, Z.G. Global scientific collaboration in COPD research. Int. J. Chronic Obstr. Pulm. Dis. 2017, 12, 215-225. [CrossRef] 
21. Yang, D.W.; Wang, X.P.; Wang, Z.C.; Yang, Z.H.; Bian, X.F. A scientometric analysis on hepatocellular carcinoma magnetic resonance imaging research from 2008 to 2017. Quant. Imaging Med. Surg. 2019, 9, 465-476. [CrossRef]

22. Chen, C.M. Science Mapping: A Systematic Review of the Literature. J. Data Inf. Sci. 2017, 2, 1-40. [CrossRef]

23. Stieb, D.M.; Chen, L.; Eshoul, M.; Judek, S. Ambient air pollution, birth weight and preterm birth: A systematic review and meta-analysis. Environ. Res. 2012, 117, 100-111. [CrossRef] [PubMed]

24. Chi, R.; Chen, C.; Li, H.Y.; Pan, L.; Zhao, B.; Deng, F.R.; Guo, X.B. Different health effects of indoor- and outdoor-originated PM2.5 on cardiopulmonary function in COPD patients and healthy elderly adults. Indoor Air 2019, 29, 192-201. [CrossRef] [PubMed]

25. McConnell, R.; Islam, T.; Shankardass, K.; Jerrett, M.; Lurmann, F.; Gilliland, F.; Gauderman, J.; Avol, E.; Kunzli, N.; Yao, L.; et al. Childhood Incident Asthma and Traffic-Related Air Pollution at Home and School. Environ. Health Perspect. 2010, 118, 1021-1026. [CrossRef] [PubMed]

26. Clark, N.A.; Demers, P.A.; Karr, C.J.; Koehoorn, M.; Lencar, C.; Tamburic, L.; Brauer, M. Effect of Early Life Exposure to Air Pollution on Development of Childhood Asthma. Environ. Health Perspect. 2010, 118, 284-290. [CrossRef] [PubMed]

27. Oberg, M.; Jaakkola, M.S.; Woodward, A.; Peruga, A.; Pruss-Ustun, A. Worldwide burden of disease from exposure to second-hand smoke: A retrospective analysis of data from 192 countries. Lancet 2011, 377, 139-146. [CrossRef]

28. Volk, H.E.; Lurmann, F.; Penfold, B.; Hertz-Picciotto, I.; McConnell, R. Traffic-Related Air Pollution, Particulate Matter, and Autism. JAMA Psychiatry 2013, 70, 71-77. [CrossRef]

29. Glasson, E.J.; Bower, C.; Petterson, B.; de Klerk, N.; Chaney, G.; Hallmayer, J.F. Perinatal factors and the development of autism-A population study. Arch. Gen. Psychiatry 2004, 61, 618-627. [CrossRef]

30. Becerra, T.A.; Wilhelm, M.; Olsen, J.; Cockburn, M.; Ritz, B. Ambient Air Pollution and Autism in Los Angeles County, California. Environ. Health Perspect. 2013, 121, 380-386. [CrossRef]

31. Chambers, L.; Finch, J.; Edwards, K.; Jeanjean, A.; Leigh, R.; Gonem, S. Effects of Personal Air Pollution Exposure on Asthma Symptoms, Lung Function and Airway Inflammation. Thorax 2017, 72, A195-A196.

32. Gauderman, W.J.; Urman, R.; Avol, E.; Berhane, K.; McConnell, R.; Rappaport, E.; Chang, R.; Lurmann, F.; Gilliland, F. Association of improved air quality with lung development in children. N. Engl. J. Med. 2015, 372, 905-913. [CrossRef] [PubMed]

33. Huang, J.; Pan, X.; Guo, X.; Li, G. Health impact of China's Air Pollution Prevention and Control Action Plan: An analysis of national air quality monitoring and mortality data. Lancet Planet. Health 2018, 2, e313-e323. [CrossRef]

34. Fitch, M.N.; Phillippi, D.; Zhang, Y.; Lucero, J.; Pandey, R.S.; Liu, J.; Brower, J.; Allen, M.S.; Campen, M.J.; McDonald, J.D.; et al. Effects of inhaled air pollution on markers of integrity, inflammation, and microbiota profiles of the intestines in Apolipoprotein E knockout mice. Environ. Res. 2019, 181, 108913. [CrossRef] [PubMed]

35. Bilenko, N.; van Rossem, L.; Brunekreef, B.; Beelen, R.; Eeftens, M.; Hoek, G.; Houthuijs, D.; de Jongste, J.C.; van Kempen, E.; Koppelman, G.H.; et al. Traffic-related air pollution and noise and children's blood pressure: Results from the PIAMA birth cohort study. Eur. J. Prev. Cardiol. 2015, 22, 4-12. [CrossRef]

36. Tian, L.; Zeng, Q.; Dong, W.T.; Guo, Q.; Wu, Z.T.; Pan, X.C.; Li, G.X.; Liu, Y. Addressing the source contribution of PM2.5 on mortality: An evaluation study of its impacts on excess mortality in China. Environ. Res. Lett. 2017, 12, 104016. [CrossRef]

37. Huang, J.; Li, G.; Qian, X.; Xu, G.; Zhao, Y.; Huang, J.; Liu, Q.; He, T.; Guo, X. The burden of ischemic heart disease related to ambient air pollution exposure in a coastal city in South China. Environ. Res. 2018, 164, 255-261. [CrossRef]

38. Guo, P.; Chen, Y.; Wu, H.; Zeng, J.; Zeng, Z.; Li, W.; Zhang, Q.; Huo, X.; Feng, W.; Lin, J.; et al. Ambient air pollution and markers of fetal growth: A retrospective population-based cohort study of 2.57 million term singleton births in China. Environ. Int. 2020, 135, 105410. [CrossRef]

(C) 2020 by the authors. Licensee MDPI, Basel, Switzerland. This article is an open access article distributed under the terms and conditions of the Creative Commons Attribution (CC BY) license (http://creativecommons.org/licenses/by/4.0/). 